\title{
Cardiothoracic
}

Transplantation

\section{Enhancement of the functional benefits of skeletal myoblast transplantation by means of coadministration of hypoxia-inducible factor $1 \alpha$}

\author{
Kasra Azarnoush, MD, ${ }^{a}$ Agnès Maurel, PhD, ${ }^{a}$ Laurent Sebbah, MD, ${ }^{\mathrm{b}, \mathrm{c}}$ Claire Carrion, ${ }^{\mathrm{d}}$ Alvine Bissery, MSc, ${ }^{\mathrm{e}}$ \\ Chantal Mandet, ${ }^{f}$ Julia Pouly, MD, ${ }^{a, g}$ Patrick Bruneval, MD, ${ }^{f, h}$ Albert A. Hagège, MD, PhD, ${ }^{a, b, c}$ and \\ Philippe Menasché, MD, $\mathrm{PhD}^{\mathrm{a}, \mathrm{c}, \mathrm{g}}$
}

From INSERM, U 633, Laboratoire d'Etude des Greffes et Prothèses Cardiaques, ${ }^{\mathrm{a}}$ Hôpital Broussais, Paris, France; U 582, ${ }^{\mathrm{d}}$ Groupe Hospitalier Pitié-Salpêtrière, Paris, France; U 430, ${ }^{f}$ Hôpital Broussais, Paris, France; Assistance Publique-Hôpitaux de Paris, Hôpital Européen Georges Pompidou, the Departments of Cardiology, ${ }^{\mathrm{b}}$ Cardiovascular Surgery, ${ }^{\mathrm{g}}$ and Pathology, ${ }^{\mathrm{h}}$ and the Clinical Investigation Center/INSERM, ${ }^{\mathrm{e}}$ Paris, France; University of Paris 5 Rene-Descartes, ${ }^{\mathrm{c}}$ Paris, France.

This work was partly supported by a grant from the Fondation de l'Avenir.

Received for publication June 4, 2004; revisions received Oct 27, 2004; accepted for publication Nov 2, 2004.

Address for reprints: Philippe Menasché, $\mathrm{MD}, \mathrm{PhD}$, Department of Cardiovascular Surgery, Hôpital Européen Georges Pompidou, 20, rue Leblanc, 75015 Paris, France (E-mail: philippe.menasche@hop.egp.aphop-paris.fr).

J Thorac Cardiovasc Surg 2005;130:173-9

$0022-5223 / \$ 30.00$

Copyright (c) 2005 by The American Association for Thoracic Surgery

doi:10.1016/j.jtcvs.2004.11.044
Objective: Early cell death remains a major limitation of skeletal myoblast transplantation. Because the poor vascularization of the target scars contributes to cell loss, we assessed the effects of combining skeletal myoblast transplantation with administration of hypoxia-inducible factor $1 \alpha$, a master gene that controls the expression of a wide array of angiogenic factors.

Methods: A myocardial infarction was created in 56 rats by means of coronary artery ligation. Eight days later, rats were randomly allocated to receive in-scar injections of culture medium (control animals, $\mathrm{n}=11)$, skeletal myoblasts $\left(5 \times 10^{6}\right.$, $\mathrm{n}=13)$, adenovirus-encoded hypoxia-inducible factor $1 \alpha\left(1.0 \times 10^{10} \mathrm{pfu} / \mathrm{mL}, \mathrm{n}=\right.$ $7)$, or skeletal myoblasts $\left(5 \times 10^{6}\right)$ in combination with an empty vector $(n=3)$ or active hypoxia-inducible factor $1 \alpha\left(1.0 \times 10^{10} \mathrm{pfu} / \mathrm{mL}, \mathrm{n}=13\right)$. A fifth group $(\mathrm{n}=9)$ underwent a staged approach in which hypoxia-inducible factor $1 \alpha(1.0 \times$ $10^{10} \mathrm{pfu} / \mathrm{mL}$ ) was injected at the time of infarction, followed 8 days later by skeletal myoblasts $\left(5 \times 10^{6}\right)$. Left ventricular function was assessed echocardiographically before transplantation and 1 month thereafter. Explanted hearts were then processed for the immunohistochemical detection of myotubes, quantification of angiogenesis, myoblast engraftment, and cell survival.

Results: Baseline ejection fractions were not significantly different among groups (35\%-40\%). One month later, ejection fraction had decreased from baseline in control hearts and in those injected with hypoxia-inducible factor $1 \alpha$. In contrast, it did not deteriorate after injections of skeletal myoblasts alone or combined with either the empty vector or active hypoxia-inducible factor $1 \alpha$ administered sequentially. The most striking change occurred in the skeletal myoblast plus hypoxiainducible factor $1 \alpha$ combined group in which ejection fraction increased dramatically (by 27\%) above baseline levels and was thus markedly higher than in all other groups $(P=.0001$ and $P=.001$ vs control animals and animals receiving hypoxia-inducible factor $1 \alpha$, respectively). Compared with skeletal myoblasts alone, the coadministration of hypoxia-inducible factor $1 \alpha$ resulted in a significantly greater degree of angiogenesis, cell engraftment, and cell survival.

Conclusion: Induction of angiogenesis is an effective means of potentiating the functional benefits of myoblast transplantation, and hypoxia-inducible factor $1 \alpha$ can successfully achieve this goal. 
$\mathrm{O}$ ver the past years, cell transplantation has emerged as a potential new therapeutic option in patients with heart failure. ${ }^{1}$ This approach is based on a substantial number of experimental studies that have demonstrated that implantation of different cell types (primarily skeletal myoblasts, ${ }^{2-5}$ bone marrow-derived mesenchymal cells, ${ }^{6}$ and embryonic stem cells ${ }^{7}$ ) into scar tissue could rejuvenate these areas through favorable changes in extracellular matrix remodeling, ${ }^{8}$ direct contribution to contractile activity, ${ }^{9}$ and/or paracrinally mediated recruitment of a resident pool of cardiac stem cells. ${ }^{10,11}$ These data have paved the way for early clinical surgical ${ }^{12}$ or catheterbased $^{13}$ trials, the functional results of which, although encouraging, need to be further validated by randomized trials, some of which are already underway.

However, a major limiting factor of the procedure is the massive rate of graft death occurring shortly after the injections,${ }^{14}$ largely because of the ischemic nature of the environment in which the cells are implanted. This assumption has thus led to the concept that, correlatively, cell survival and the expectedly related functional improvement might be increased by enhancing the vascular supply of the grafted area. The present study was therefore designed to test this hypothesis by assessing, in a rat model of myocardial infarction, the effects of combining skeletal myoblast transplantation with hypoxia-inducible factor $1 \alpha$ (HIF-1 $\alpha)$, a master gene that controls the expression of several genes encoding angiogenic growth factors. ${ }^{15,16}$

\section{Methods}

The experiments complied with the "Principles of Laboratory Animal Care" formulated by the National Society for Medical Research and the "Guide for the Care and Use of Laboratory Animals" prepared by the Institute of Laboratory Animal Resources, Commission on Life Science, National Research Council, and published by the National Academy Press, revised 1996.

\section{Cell Cultures}

Primary muscle cell cultures were prepared from newborn Wistar male rats (Charles Rivers, Arbresle, France) by using a previously established protocol. ${ }^{2}$ The day of transplantation, cells were thawed and washed 3 times in modified Eagle's medium with $0.5 \%$ bovine serum albumin (fraction V; Sigma, St Louis, Mo). Samples of $5 \times 10^{6}$ cells were prepared and kept at room temperature until transplantation. Viability and the percentage of skeletal myoblasts were assessed by means of trypan blue exclusion and desmin immunolabeling, respectively.

\section{HIF-1 $\alpha$}

The HIF-1 $\alpha / \mathrm{VP}-16$ hybrid was constructed by truncating HIF- $1 \alpha$ at amino acid 390 and then joining the transactivation domain of herpes simplex virus VP-16 downstream. Gene expression is controlled by the cytomegalovirus immediate early enhancerpromoter. The efficacy of this HIF-1 $1 \alpha / \mathrm{VP}-16$ construct has been demonstrated both in vitro and in animal experiments. ${ }^{17,18}$ In the present study the construct was inserted into the genome of an adenoviral 2 vector (Genzyme BioSurgery, Cambridge, Mass), as described previously. ${ }^{19,20}$ The empty vector was constructed in a fashion similar to that of Ad2/HIF-1 $\alpha / \mathrm{VP} 16$, except that it lacked a transgene; as such, it has been shown to only induce a mild and transient inflammatory response that does not generate noticeable angiogenic effects.

\section{Myocardial Infarction Model}

Female Wistar rats (Charles Rivers) were anesthetized with isoflurane $(1 \%-3 \%)$ with a constant flow of oxygen $(1-2 \mathrm{~L} / \mathrm{min})$ and ventilated with an endotracheal tube. A myocardial infarction was then created through ligation of the left coronary artery with a 6-0 polypropylene snare (Ethicon Inc, Somerville, NJ) through a left lateral thoracotomy.

\section{Experimental Protocol}

Eight days after creation of infarction, the chest was reopened through a median sternotomy. Simultaneously, the cells were thawed and pelleted. Rats were then randomly allocated to receive intramyocardial injections of culture medium alone (control animals, $\mathrm{n}=11)$, skeletal myoblasts alone $\left(5 \times 10^{6}, \mathrm{n}=13\right)$, adenovirus-encoded HIF- $1 \alpha$ alone $\left(1.0 \times 10^{10} \mathrm{pfu} / \mathrm{mL}, \mathrm{n}=7\right)$, or skeletal myoblasts $\left(5 \times 10^{6}\right)$ in combination with either the empty vector for HIF-1 $\alpha(\mathrm{n}=3)$ or active HIF- $1 \alpha\left(1.0 \times 10^{10} \mathrm{pfu} / \mathrm{mL}\right.$, $\mathrm{n}=13$ ) after mixing of the 2 solutions in the same syringe. A fifth group $(\mathrm{n}=9)$ underwent a staged approach, in that HIF-1 $\alpha(1.0 \times$ $10^{10} \mathrm{pfu} / \mathrm{mL}$ ) was injected at the time of infarction, whereas skeletal myoblasts $\left(5 \times 10^{6}\right)$ were delivered in a usual manner 8 days later.

All injections consisted of a $150-\mu \mathrm{L}$ volume, which was delivered in 4 or 5 sites in the core and at the borders of the scar by using a 29 -gauge needle.

Immunosuppression with cyclosporine (INN: ciclosporin; 10 $\mathrm{mg} / \mathrm{kg}$; Novartis Pharma, Rueil-Malmaison, France) was started at the time of myocardial infarction and continued thereafter until death.

\section{End Points}

Left ventricular function. Left ventricular (LV) function was assessed by means of 2-dimensional echocardiography shortly before injections (ie, 6 and 8 days after infarction) and 1 month thereafter according to a previously described protocol. ${ }^{2}$ After endocardial tracings with the leading-edge method, measurements of maximal LV long-axis lengths and areas were performed on cine loops at end diastole (at the time of apparent maximal cavity dimension) and end systole (at the time of maximum anterior motion of the posterior wall). These data were then used to calculate LV end-diastolic volume (LVEDV) and LV end-systolic volume (LVESV) and ejection fraction (EF; $E F(\%)=100 \times$ (LVEDV - LVESV)LVEDV) by using the single-plane area-length method $V=8 A^{2} 3 \pi L$. All measurements were made by a single experienced observer who was blinded to the treatment group. Measurements were averaged over 3 to 5 consecutive cardiac cycles.

Cell engraftment and angiogenesis. After the last echocardiographic assessment, the animals were killed. Because the primary objective of this study was to assess whether the additional pro- 
tection expected from HIF- $1 \alpha$ was related to increased angiogenesis, only hearts injected with either myoblasts alone or myoblasts in combination with HIF- $1 \alpha$ were used for this part of the protocol. Hearts of these 2 groups were harvested and separated in 2 halves by a short-axis section through the midportion of the infarcted area. Histologic and immunohistochemical studies were carried out from the 2 blocks of each heart on 5- $\mu$ m-thick cryostat sections fixed in acetone for 10 minutes. For histologic assessment (ie, extent of scarring and myoblast engraftment), the sections were stained with toluidine blue. For immunohistochemistry, a standard 3-step alkaline phosphatase (red labeling) technique, peroxidase (brown labeling) technique, or both was used to detect skeletal myogenic cells (red labeling) with a monoclonal antibody against the skeletal muscle fast myosin heavy chain isoform (clone My32, Sigma) or rat endothelial cells (brown labeling) with the anti-rat endothelial cell monoclonal antibody (RECA; Serotec, Oxford, United Kingdom), or both with combined immunohistochemistry on the same tissue section.

For each rat, the heart section containing the best engraftment of skeletal myocytes was selected for quantification of angiogenesis. To this end, the number of RECA-labeled capillary sections was counted in an average of 10 randomly selected microscopic fields by using a light microscope with a grid-eye piece at a magnification of $10 \times$ and expressed as a number per unit of area $\left(625 \mu \mathrm{m}^{2}\right)$. The percentage of engraftment was calculated as the ratio of the myosin-positive area to the infarcted area, as measured with computerized planimetry.

Cell survival. In a subset of experiments involving transplantation of male myoblasts into female recipients, left ventricles removed at the end of the study were snap-frozen in liquid nitrogen and stored at $-80^{\circ} \mathrm{C}$. Muscles were thawed on ice, minced, and digested to homogeneity overnight at $4^{\circ} \mathrm{C}$ in lysis buffer (Roche, Basel, Switzerland). DNA was then isolated from whole homogenates by using the Wizard DNA purification kit (Promega, Charbonnieres, France) and dissolved in Tris- $\mathrm{HCl}$ buffer $(5 \mathrm{mmol} / \mathrm{L}$, $\mathrm{pH} 8.5)$.

To determine the amount of male cells, we used SYBERGreen (Applied Biosystems, Foster City, Calif) double-stranded, DNAbinding, dye chemistry-based, real-time, quantitative polymerase chain reaction (PCR). A rat $\mathrm{Y}$ chromosome-specific sequence in the sex-determining region y (sry) gene was used to determine the relative quantities of male cells after transplantation. Primers used, 5' -CAGACTCATCGAAGGG-3' (forward) and 5'-AGTCCTCCAAGAACCAG-3' (reverse), were designed with the Primer Express software (Applied Biosystems). Known quantities $(1.5 \times$ $10^{-7}$ to $1.5 \times 10^{-10} \mathrm{~g} / \mathrm{L}$ ) of a pGEM-T easy vector containing the 161-bp fragment specific for the sry gene (pGEM-Teasy-SRY161), generated by means of PCR amplification with the abovedescribed Y chromosome-specific primers, were used as internal standards for amplification efficiency and specificity. The absolute number of surviving cells compared with those initially transplanted was extrapolated from the standard curve established with dilutions of genomic DNA extracted from known numbers of male rat cells $\left(2.5 \times 10^{6}\right.$ to $\left.10 \times 10^{6}\right)$ injected in a separate set of infarcted female hearts. There was an excellent correlation between the number of injected cells and the amount of sry PCR products, and as for $2.5,5,7.5$, and $10 \times 10^{6}$ cells, the amount of fluorescence (measured in triplicate for each batch of cells) aver-

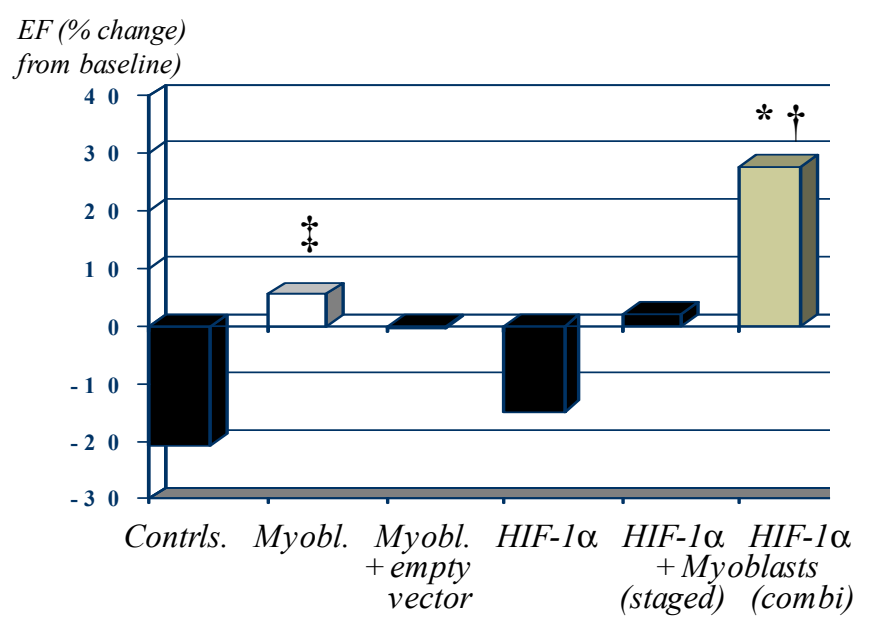

Figure 1. Posttransplantation EFs. Contrls, Control animals; myobl, myoblasts. The staged group refers to the injection of HIF-1 $\alpha$ at the time of infarction, followed 8 days later by myoblast transplantation; the combi group refers to the concomitant administration of HIF-1 $\alpha$ and myoblasts 8 days after myocardial infarction. ${ }^{*} \boldsymbol{P}=.0001$ versus control animals, $\boldsymbol{P}=.001$ versus HIF-1 $\alpha$ (after adjustment for multiple comparison analysis). $+\boldsymbol{P}=$ .03 versus myoblasts (not statistically significant after adjustment for multiple comparisons). $¥ P=.006$ versus control animals, $P=$ .03 versus HIF-1 $\alpha$ (not statistically significant after adjustment for multiple comparisons).

aged $2.62 \times 10^{-2}, 6.16 \times 10^{-2}, 9.83 \times 10^{-2}$, and $14.2 \times 10^{-2}$, respectively (goodness of fit, 0.84 ).

\section{Data Analysis}

All functional and histologic studies were performed in a blinded fashion. Because of the inappropriateness of assuming a Gaussian distribution of values given the small sample sizes, nonparametric tests were used for comparing between-group and within-group differences (Mann-Whitney and Wilcoxon tests, respectively). For that same reason, results are expressed as median (minimalmaximal) values. The critical $\alpha$ level was set at .05 , and the Holm method was used to adjust for multiple comparisons.

\section{Results}

\section{Characterization of Injectates}

At the time of transplantation, the percentage of myogenic cells, as assessed by using a positive staining for desmin, was $38.6 \%$. The postthawing viability rate, as assessed by means of exclusion of trypan blue, was $91 \%$.

\section{Functional Outcomes}

Baseline echocardiographically determined EFs, expressed as median values, ranged from $30.6 \%$ to $41.6 \%$ but were not significantly different among groups, as assessed by means of nonparametric testing. However, 1 month after transplantation, there were marked treatment effects (Figure 1) that can be summarized as follows: EF decreased from baseline 
TABLE 1. Changes in left ventricular volumes

\begin{tabular}{|c|c|c|c|c|}
\hline \multirow[b]{2}{*}{ Group } & \multicolumn{2}{|c|}{ EDV (mL) } & \multicolumn{2}{|c|}{ ESV (mL) } \\
\hline & Baseline & After Tx & Baseline & After Tx \\
\hline Control animals $(\mathrm{n}=11)$ & $0.40(0.32-0.49)$ & $0.55(0.41-1.08)$ & $0.25(0.20-0.32)$ & $0.40(0.22-0.86)$ \\
\hline Myoblasts ( $\mathrm{n}=13$ ) & $0.43(0.26-0.53)$ & $0.53(0.34-0.99)$ & $0.30(0.15-0.39)$ & $0.37(0.14-0.73)$ \\
\hline Myoblasts + empty vector $(n=3)$ & $0.44(0.36-0.47)$ & $0.64(0.41-0.64)$ & $0.24(0.21-0.35)$ & $0.37(0.24-0.47)$ \\
\hline HIF-1 $\alpha(n=7)$ & $0.37(0.30-0.44)$ & $0.50(0.36-0.75)$ & $0.22(0.17-0.30)$ & $0.30(0.24-0.65)$ \\
\hline Myoblasts + HIF-1 $\alpha$ (staged, $\mathrm{n}=9$ ) & $0.38(0.28-0.58)$ & $0.63(0.34-0.82)$ & $0.27(0.16-0.41)$ & $0.38(0.21-0.59)$ \\
\hline Myoblasts + HIF- $1 \alpha$ (combined, $n=13)$ & $0.41(0.28-0.51)$ & $0.50(0.38-1.08)$ & $0.24(0.19-0.38)$ & $0.28(0.18-0.83)$ \\
\hline
\end{tabular}

Data are expressed as median (minimal-maximal) values. In the staged group hypoxia-inducible factor $1 \alpha$ was injected at the time of infarction (ie, 8 days before myoblast transplantation); in the combined group both hypoxia-inducible factor $1 \alpha$ and myoblasts were injected simultaneously 8 days after myocardial infarction. EDV, End-diastolic volume; ESV, end-systolic volume; $T x$, transplantation; HIF-1 $\alpha$, hypoxia-inducible factor $1 \alpha$.

in control hearts (from $38.7 \%$ [31.6\%-44.9\%] to $29.1 \%$ [8.5\%-46.8\%]; relative decrease, $-20.7 \%)$ and in hearts injected with HIF- $1 \alpha$ (from $40.4 \%$ [27.9\%-43.9\%] to $34.4 \%$ [13.3\%-46.1\%]; relative decrease, $-14.9 \%)$. In contrast, EF did not deteriorate over time after injections of skeletal myoblasts, irrespective of whether they were given alone (before, 30.6\% [24.8\%-40.7\%]; after, 34.9\% [24.7\%$57.3 \%$ ]; relative increase, $5.6 \%$ ) or in combination with either active HIF- $1 \alpha$ given sequentially (before, 35.2\%
[27.1\%-42.8\%]; after, $37.0 \%$ [19.7\%-48.6\%]; relative increase, $2.2 \%$ ) or the empty adenoviral vector (before, $41.6 \%$ [24.6\%-45.2\%]; after, $41.5 \%$ [25.1\%-42.1\%]), although the small size of this latter sample limits the meaningfulness of the conclusions. The most striking change occurred in the group receiving concomitant delivery of myoblasts and HIF- $1 \alpha$ because EF increased dramatically above baseline levels (before, 34.9\% [25.0\%-44.3\%]; after, $44.8 \%$ [22.9\%$56.2 \%$ ]; relative increase, $27.6 \%$ ), so that at the 1 -month

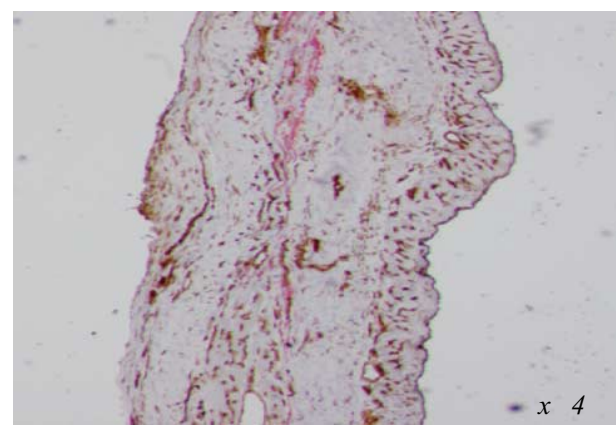

My oblast

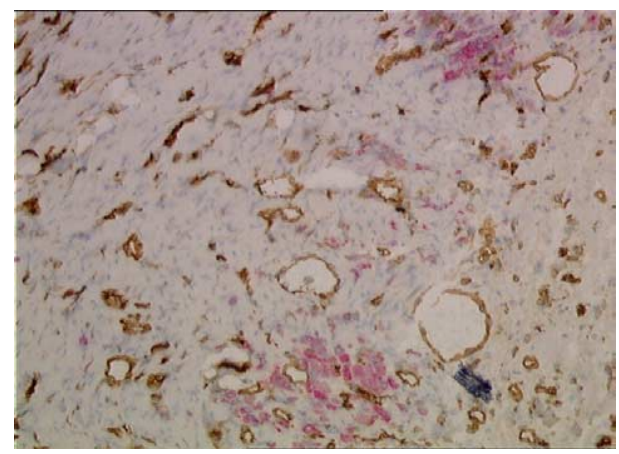

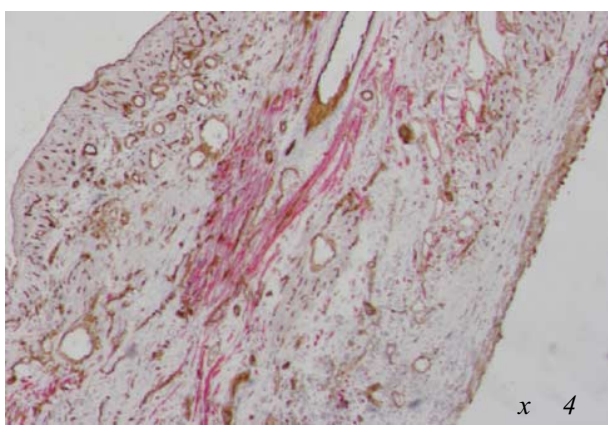

M y oblast + HIF

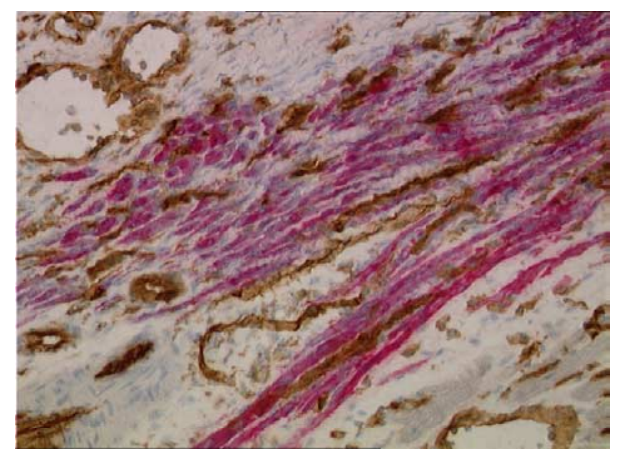

Figure 2. Representative picture of a myoblast-transplanted heart (left panel) and a heart treated with both myoblasts and HIF-1 $\alpha$ (right panel). At higher magnification $(20 \times)$, the greater degree of angiogenesis (brown staining) and fast skeletal myosin-positive cell engraftment (red staining) is clearly visible in the heart receiving combined therapy. 
study point, it was markedly higher than in all other groups, the difference being significant versus control animals and HIF- $1 \alpha$-injected hearts $(P=.0001$ and $P=.001$, respectively). This improvement was primarily related to smaller changes in LV end-systolic volumes (Table 1), which only increased by $7.7 \%$ above baseline in hearts receiving myoblasts and HIF- $1 \alpha$, a figure 10-fold, 7-fold, and 4-fold lower than those yielded by control animals, HIF- $1 \alpha$-treated hearts, and myoblast-grafted hearts, respectively. Conversely, there were no treatment-related effects on the postinfarction remodeling process, as assessed on the basis of the similar increase in LV diastolic volumes among the different experimental groups (Table 1).

\section{Cell Engraftment and Angiogenesis}

Clusters of myoblasts were identified by means of histology as large multinucleated myocytes and mainly by means of immunohistochemistry as myocytes staining positively for myosin heavy chain both in the core and in the borders of the scar. In the group receiving both myoblasts and HIF- $1 \alpha$ concomitantly, cell engraftment was associated with a significantly greater angiogenesis in the core of the infarct and along its borders with normal myocardium compared with that seen in the myoblast-alone group (Figure 2), the number of capillaries per unit area being $8.5 \times 10-4(4.6 \times$ $\left.10^{-4}-1.1 \times 10^{-3}\right)$ and $5.3 \times 10^{-4}\left(3.8 \times 10^{-4}-6.5 \times\right.$ $\left.10^{-4}\right)$, respectively $(P=.023)$. The extent of cell engraftment into the injected scars was also greater in the combined group than in hearts receiving myoblasts alone, as reflected by a percentage of myosin-positive areas relative to the LV infarcted area of $4.49 \%(0.44 \%-18.35 \%)$ versus $0.95 \%(0.16 \%-7.21 \%[P=.027])$. There was no tumor formation in any heart studied.

\section{Cell Survival}

In the subset of experiments in which male myoblasts were injected into female recipients, the number of grafted cells, identified by the presence of a Y chromosome by means of PCR, was also significantly greater after simultaneous coinjections of myoblasts and HIF- $1 \alpha$ than after cell transplantation alone: $13.16 \times 10^{6}\left(3.45 \times 10^{6}-20.89 \times 10^{6}\right)$ versus $1.56 \times 10^{6}\left(0.67 \times 10^{6}-3.42 \times 10^{6}[P=.020, \mathrm{n}=4\right.$ for each group]).

\section{Discussion}

\section{Main Findings of the Study}

The most salient finding of the present study is that the concomitant intramyocardial administration of HIF- $1 \alpha$ and skeletal myoblasts improved postinfarction LV systolic function to a greater extent than myoblast grafting alone and that this improvement correlated with an increase in angiogenesis, cell survival, and graft area. Conversely, HIF- $1 \alpha$ given at the time of infarction failed to provide a similar benefit, possibly because of adenoviral inactivation by inflammatory and immune processes (cyclosporine might have not yet been effective at the time of HIF- $1 \alpha$ injection because it had just been started). This hypothesis is indirectly supported by the fact that in the study in which sequential administration of basic fibroblast growth factor and fetal cardiomyocytes (injected one week later) was functionally successful, the factor was incorporated into controlled-release gelatin hydrogels, ${ }^{21}$ which might have provided some protection against environmental inactivating processes. In contrast, Retuerto and colleagues ${ }^{22}$ recently reported that intramyocardial injections of an adenovirus encoding vascular endothelial growth factor at the time of infarction enhanced the benefits of fetal cardiomyocyte transplantation performed 3 weeks later. Several differences in protocol design, particularly the use of syngeneic animals in Retuerto's experiments, might account for this discrepancy with our data. Furthermore, the lack of functional benefits in hearts injected with HIF- $1 \alpha$ alone is consistent with the prediction that increasing angiogenesis in scar tissue that no longer harbors blood flow-dependent cardiomyocytes is unlikely to affect the contractile patterns of that fibrous area. This assumption is actually supported by the observation that the group that yielded the best functional outcome was the one in which HIF- $1 \alpha$ was delivered concomitantly with living cells (ie, the grafted myoblasts), the survival of which is expected to benefit from angiogenesis.

\section{Magnitude and Prevention of Posttransplantation Cell Death}

Up to $90 \%$ of cardiomyocytes have been reported to die over the first 48 hours after their intramyocardial implantation, ${ }^{14}$ and a similar attrition rate has been observed with skeletal myoblasts transplanted in skeletal muscle ${ }^{23}$ or in infarcted myocardial areas (unpublished observations from our laboratory). This major loss of grafted cells is likely to seriously hamper the functional efficacy of the procedure, as suggested by the close relationship established in a rat model of myocardial infarction between the number of injected myoblasts and the extent of LV preservation. ${ }^{24}$

A first approach consists of increasing the number of cells to compensate for the loss of transplanted cells, but this strategy is plagued with limitations related to practicality (the duration of cultures should remain within the clinically acceptable time frame of 2-3 weeks), cost, and safety (the tolerable volume that can be injected intramyocardially should probably not exceed 5-6 mL, whereas multiple passages might favor the emergence of a differentiationdefective population of cells with a subsequent risk of inappropriate graft overgrowth). ${ }^{25}$ An alternate approach targets the enhancement of cell survival by counteracting the mechanisms of graft loss. 
These mechanisms are likely multiple, but apart from physical strain during injections and the inflammatory reaction triggered by needle punctures, two seem to play a major role: apoptosis, as demonstrated by the benefits of transfecting mesenchymal stem cells with a prosurvival gene (Akt) before transplantation ${ }^{26}$ and ischemia, as demonstrated by the 2-fold greater increase in cell survival when injections are made into a richly vascularized tissue, as opposed to a fibrous scar. ${ }^{14}$ The results of our myoblasts and HIF- $1 \alpha$ group support this concept that enhancing the vascular supply of the grafted cells optimizes the posttransplantation functional outcomes by addressing the ischemic component of cell loss through increased angiogenesis.

As such, our data are consistent with those of previous studies that have established the benefits of completing cell transplantation by an additional supply of angiogenic growth factors. Thus both genetically induced overexpression of vascular endothelial growth factor by skeletal myoblasts $^{27,28}$ or early differentiated embryonic stem cells ${ }^{29}$ and sequential delivery of fibroblast growth factor and fetal cardiomyocyte $^{21}$ have been shown to increase angiogenesis and improve function compared with results seen in control animals. However, it is now recognized that administration of a single angiogenic growth factor has a limited therapeutic efficacy, ${ }^{30}$ hence the rationale for the delivery of a mix of them or, preferably, of a master gene that can control the expression of a wider array of downstream effectors. In this setting HIF- $1 \alpha$ is attractive because of its role as a key regulator of gene expression in response to cellular hypoxia and the multiplicity of its transcriptionally activated target genes $(>80)$ whose protein products play crucial roles in angiogenesis (particularly through production of vascular endothelial growth factor and erythropoietin), cell protection, and metabolic mechanisms (particularly glucose transport and glycolysis). ${ }^{15}$ Thus although HIF- $1 \alpha$ alone failed to prevent a deterioration of LV function, the observation that its concomitant delivery with skeletal myoblasts further potentiated the cell-mediated benefits (Figure 2) suggests a synergistic action and thus a contribution of both myogenesis and angiogenesis to the improved functional outcome yielded by the combined therapy group.

\section{Study Limitations}

Several limitations of the study need, however, to be acknowledged. First, evidence for the efficacy of HIF- $1 \alpha$ is primarily based on surrogate end points like capillary density and LV functional indices because we did not measure directly the expression of HIF- $1 \alpha$ in myocardial tissue. However, the ability of an adenovirus to act as an efficacious vector of HIF- $1 \alpha$ has been previously demonstrated by the upregulation of a wide array of HIF- $1 \alpha$-dependent genes in human cardiac cells transfected by these constructs. $^{20}$
Second, in this study the gene encoding HIF- $1 \alpha$ was delivered by an adenoviral vector in solution coinjected along with myoblasts. It remains thus possible that a greater therapeutic efficacy might have been obtained by alternate modes of gene delivery (direct myoblast transfection and naked plasmid DNA ${ }^{17}$ ) or cotransplantation of cells featuring an angiogenic potential. ${ }^{26,31,32}$

Third, our PCR data demonstrated an almost 3-fold greater number of $\mathrm{Y}$ chromosome-bearing cells in the combined therapy group than in the myoblast-alone group. This likely reflects an improved survival of better-vascularized myoblasts, as suggested by the greater extent of skeletal myosin-positive areas seen in these hearts receiving myoblasts plus HIF-1 $\alpha$. Nevertheless, in the absence of a detailed phenotypic characterization, we cannot exclude that the proliferation of the nonmyogenic cell component of the initial injectate (ie, fibroblasts and endothelial cells) might have also contributed to this higher cell count.

Finally, follow-up was limited to 1 month. The relatively short half-life of adenoviral vectors then raises the question of the long-term effects of HIF- $1 \alpha$ therapy, but the bulk of cell death occurs shortly after injections ${ }^{14}$ at a time at which HIF- $1 \alpha$ is still present for triggering an increased angiogenesis, which is then expected to persist over time, even if the trigger has waned.

In conclusion, the present data show that the functional benefits of skeletal myoblast transplantation can be significantly enhanced by the concomitant administration of an adenoviral vector encoding HIF- $1 \alpha$, which supports an important role for ischemia in the genesis of posttransplantation cell death and suggests that enhancing graft vascularization is an effective means of overcoming this problem. The potential clinical relevance of these results stems from the approval of HIF- $1 \alpha$ for investigational use in phase I human trials. More generally, the current findings also illustrate the benefits that can be derived from the synergistic effects of gene and cell therapy.

\section{References}

1. Menasché P. Skeletal myoblast transplantation for cardiac repair. Expert Rev Cardiovasc Ther. 2004;2:21-8.

2. Scorsin M, Hagege A, Vilquin JT. Fiszman M, Marotte F, Samuel JL, et al. Comparison of the effects of fetal cardiomyocyte and skeletal myoblast transplantation on post-infarct left ventricular function. J Thorac Cardiovasc Surg. 2000;119:1169-75.

3. Pouzet B, Vilquin JT, Hagege A, Scorsin M, Messas E, Fiszman M, et al. Factors affecting functional outcome following autologous skeletal myoblast transplantation. Ann Thorac Surg. 2001;71:844-50.

4. Murry CE, Wiseman RW, Schwartz SM, Hauschka SD. Skeletal myoblast transplantation for repair of myocardial necrosis. J Clin Invest. 1996;98:2512-23.

5. Taylor DA, Atkins BZ, Hungspreugs P, Jones TR, Reedy MC, Hutcheson KA, et al. Regenerating functional myocardium: improved performance after skeletal myoblast transplantation. Nat Med. 1998; 4:929-33.

6. Shake JG, Gruber PJ, Baumgartner WA, Senechal G, Meyers J, Redmond JM, et al. Mesenchymal stem cell implantation in a swine 
myocardial infarct model: engraftment and functional effects. Ann Thorac Surg. 2002;73:1919-25.

7. Min JY, Yang Y, Converso KL Liu L, Huang Q, Morgan JP, et al. Transplantation of embryonic stem cells improves cardiac function in postinfarcted rats. $J$ Appl Physiol. 2002;92:288-96.

8. Fujii T, Yau TM, Weisel RD, Ohno N, Mickle D, Shiono N, et al. Cell transplantation to prevent heart failure: a comparison of cell types. Ann Thorac Surg. 2003;76:2062-70.

9. Rubart M, Pasumarthi KB, Nakajima H, Soonpaa MH, Nakajima HO, Field LJ. Physiological coupling of donor and host cardiomyocytes after cellular transplantation. Circ Res. 2003;92:1217-24.

10. Beltrami AP, Barlucchi L, Torella D, Baker M, Limana F, Chimenti S, et al. Adult cardiac stem cells are multipotent and support myocardial regeneration. Cell. 2003;114:763-76.

11. Oh H, Bradfute SB, Gallardo TD, Nakamura T, Gaussin V, Mishina Y, et al. Cardiac progenitor cells from adult myocardium: homing, differentiation, and fusion after infarction. Proc Natl Acad Sci U S A. 2003;100:12313-8.

12. Menasche P, Hagege AA, Vilquin JT, Desnos M, Abergel E, Pouzet B, et al. Autologous skeletal myoblast transplantation for severe postinfarction left ventricular dysfunction. J Am Coll Cardiol. 2003;41: 1078-83.

13. Smits PC, van Geuns RJ, Poldermans D Bountioukos M, Onderwater $\mathrm{E}$, Lee $\mathrm{CH}$, et al. Catheter-based intramyocardial injection of autologous skeletal myoblasts as a primary treatment of ischemic heart failure: clinical experience with six-month follow-up. $\mathrm{J}$ Am Coll Cardiol. 2003;42:2063-9.

14. Zhang M, Methot D, Poppa V, Fujio Y, Walsh K, Murry CE. Cardiomyocyte grafting for cardiac repair: graft cell death and anti-death strategies. J Mol Cell Cardiol. 2001;33:907-21.

15. Semenza GL. HIF-1 and tumor progression: pathophysiology and therapeutics. Trends Mol Med. 2002;8(suppl):S62-7.

16. Semenza GL. Hypoxia inducible nuclear factors bind to an enhancer element located $3^{\prime}$ to the human erythropoietin gene. Proc Natl Acad Sci U S A. 1991;88:5680-4.

17. Vincent KA, Shyu KG, Luo Y, Magner M, Tio RA, Jiang C, et al. Angiogenesis is induced in a rabbit model of hindlimb ischemia by naked DNA encoding an HIF-1 $\alpha / \mathrm{VP}-16$ hybrid transcription factor. Circulation. 2000;102:2255-61.

18. Shyu KG, Wang MT, Wang BW, Chang CC, Leu JG, Kuan P, et al. Intramyocardial injection of naked DNA encoding HIF-1 $\alpha$ /VP-16 hybrid to enhance angiogenesis in an acute myocardial infarction model in rat. Cardiovasc Res. 2002;54:576-83.

19. Vincent KA, Feron O, Kelly RA. Harnessing the response to tissue hypoxia: HIF- $1 \alpha$ and therapeutic angiogenesis. Trends Cardiovasc Med. 2002;12:362-7.
20. Jiang C, Lu H, Vincent KA, Shankara S, Belanger AJ, Cheng SH, et al. Gene expression profiles in human cardiac cells subjected to hypoxia or expressing a hybrid form of HIF-1 $\alpha$. Physiol Genomics. 2002;8:23-32.

21. Sakakibara Y, Nishimura K, Tambara K, Yamamoto M, Lu F, Tabata $\mathrm{Y}$, et al. Prevascularization with gelatin microspheres containing basic fibroblast growth factor enhances the benefits of cardiomyocyte transplantation. J Thorac Cardiovasc Surg. 2002;124:50-6.

22. Retuerto MA, Schalch P, Patejunas G, Carbray J, Liu N, Esser K, et al. Angiogenic pretreatment improves the efficacy of cellular cardiomyoplasty performed with fetal cardiomyocyte implantation. J Thorac Cardiovasc Surg. 2004;127:1041-50.

23. Tremblay JP, Vilquin JT. Transplantation of normal or genetically modified myoblasts for the treatment of hereditary or acquired diseases. J Soc Biol. 2001;195:29-37.

24. Tambara K, Sakakibara Y, Sakaguchi G, Lu F, Premaratne GU, Lin X, et al. Transplanted skeletal myoblasts can fully replace the infracted myocardium when they survive in the host in large numbers. Circulation. 2003;108(suppl II):II259-63.

25. Reinecke H, Murry CE. Transmural replacement of myocardium after skeletal myoblast grafting into the heart. Too much of a good thing? Cardiovasc Pathol. 2000;9:337-44.

26. Askari AT, Unzek S, Popovic ZB, Goldman CK, Forudi F, Kiedrowski $\mathrm{M}$, et al. Effect of stromal-cell-derived factor 1 on stem-cell homing and tissue regeneration in ischemic cardiomyopathy. Lancet. 2003; 362:697-703.

27. Suzuki K, Murtuza B, Smolenski RT, Sammut IA, Suzuki N, Kaneda $\mathrm{Y}$, et al. Cell transplantation for the treatment of acute myocardial infarction using vascular endothelial growth factor expressing skeletal myoblasts. Circulation. 2001;104(suppl I):I207-12.

28. Yau TM, Li G, Weisel RD, Reheman A, Jia ZQ, Mickle DA, et al. Vascular endothelial growth factor transgene expression in cell-transplanted hearts. J Thorac Cardiovasc Surg. 2004;127:1180-7.

29. Yang Y, Min JY, Rana JS, Ke Q, Cai J, Chen Y, et al. VEGF enhances functional improvement of postinfarcted hearts by transplantation of ESC-differentiated cells. J Appl Physiol. 2002;93:1140-51.

30. Hughes GC, Biswas SS, Yin B, Coleman RE, DeGrado TR, Landolfo $\mathrm{CK}$, et al. Therapeutic angiogenesis in chronically ischemic porcine myocardium: comparative effects of bFGF and VEGF. Ann Thorac Surg. 2004;77:812-6.

31. Kim EJ, Li RK, Weisel RD, Mickle DA, Jia ZQ, Tomita S, et al. Angiogenesis by endothelial cell transplantation. J Thorac Cardiovasc Surg. 2001;122:963-71.

32. Ott HC, Bonaros N, Marksteiner R, Wolf D, Mardreiter E, Schachner $\mathrm{T}$, et al. Combined transplantation of skeletal myoblasts and bone marrow stem cells for myocardial repair in rats. Eur J Cardiothorac Surg. 2004;25:627-34. 